\title{
Analysis influencing factors of Students in College Physical Education Theory Course Learning in Shaanxi Province
}

\author{
Huifeng Jing \\ College of Physical Education, Yan'an University, Yan'an 716000, China \\ Jinghuifeng112@126.com
}

\begin{abstract}
The paper Used methods of literature, questionnaire survey, statistics and other methods, to conduct a comprehensive analysis of teachers and students from two angles factors College Physical Education Majors Learning Theory Course in Shaanxi Province. The results showed that: the poor student interest in learning theory courses, low learning motivation level, poor theoretical basis, teaching methods, means, teaching content selection and evaluation of teaching are the main factors affecting student learning theory courses. Through analysis, propose appropriate response measures to lay a solid theoretical foundation for the study of college sports majors better learning theory class. Currently, the prevalence of Physical Education Majors a universal phenomenon, namely emphasis on technical courses, while ignoring the grasp of professional knowledge. It manifested as more interested in practical classes, and classes for professional theory seriously enough, resulting in absenteeism, leave, increased sick leave, and do not pay attention in class, and so rampant cheating in the exam. Research on Physical Education Majors theory teaching research focuses on the psychological level, while the study of PE Theory Course Learning factors analysis did not address. Based on the PE Theory Education Course Learning Factors School of Shaanxi Province college sports research, provide a theoretical basis for the Physical Education Teaching Theory Course.
\end{abstract}

Keywords: Physical Education; Theory Course Studying; Influencing Factors.

\section{Subjects and Methods}

\subsection{Subjects}

In Physical Education Major in Shaanxi Province 2013, 2012 and 2011 students for the study.

\subsection{Research Methods}

The main use of the literature, questionnaire, mathematical statistics and logical analysis and other methods studied.

\section{Results and Analysis}

\subsection{Student's attitude of professional theory course}

As can be seen from the survey (Table1), Physical Education Majors treat open sports theory class attitude, said it was important to account for $36.3 \%$ of those surveyed, $50.7 \%$ of the number of important investigations, those surveyed generally accounted for $11.7 \%$, unimportant $1.3 \%$ of those surveyed. Shows that the theoretical knowledge is important for students accounted for about a half, there are some students study theoretical knowledge is not enough to treat that PE teachers only need good skills can be, and this phenomenon is not consistent with the requirements of the New Curriculum for PE teachers, Sport not only for athletics, now pay more attention to community health development, so physical education students pay more attention to sports theoretical knowledge. Strengthen education and guidance combine to continuously improve the basic quality of students on culture, to enable students to grasp fully recognize the importance of sports as a cross-century good theoretical knowledge of professionals in order to improve students' knowledge of learning theory due sports theory course textbook boring, monotonous, and practice from the larger, plus student and cultural basis of poor knowledge, lack of rational abstraction, technical teaching of the theory class learning but also have an impact, so the students' enthusiasm, initiative easy to play, teachers in line with the students' psychological, physical characteristics of the foundation to deal with the teaching 
content, teaching methods, teaching methods, teaching strategies, conduct a comprehensive reform, and student motivation, learning attitude, behavior, study habits, learning, emotional and other issues in-depth study in order to develop a full range of teaching seriously reform program, to conduct a thorough reform of the teaching, so that it can receive good results.

Table1 List of student circumstances attitudes of professional theory courses. (\%)

\begin{tabular}{cccc}
\hline & Male & Female & Overall \\
\hline Very important & 44.9 & 27.0 & 36.3 \\
important & 35.9 & 65.5 & 50.7 \\
General & 16.6 & 6.3 & 11.7 \\
Unimportant & 2.6 & 1.2 & 1.9 \\
\hline
\end{tabular}

\subsection{Student motivation to learn professional theory courses analysis}

Learning motivation is that students learning and learning situation has shown a relatively stable psychological tendencies. Survey shows (Table2), $14.7 \%$ of the students have the motivation to learn is to meet the test, 71.3 percent of students specializing in theoretical courses is to better grasp the movement of technical services, and PubMed and other motivated students accounted for $11.4 \%$, $2.6 \%$. Thus, some of the students to learn professional theory courses in order to pass the exam, and ultimately be able to graduate. Learned in the interview, the students meet the test are due to large seniors to instill the university exam is easy too, usually do not learn and so thought, resulting from the admission of students to learn thinking appeared tired; think better grasp of sports technology and PubMed the student is in order to enrich their theoretical knowledge, through their own efforts to learn professional knowledge, so that they can achieve their goals.

Table2 List of learning survey motivation of professional theory course. (\%)

\begin{tabular}{cccc}
\hline & Male & Female & Overall \\
\hline Meet the test & 19.2 & 10.1 & 14.7 \\
Master knowledge & 66.6 & 75.2 & 71.3 \\
Test Postgraduate & 9.0 & 13.6 & 11.4 \\
Other & 5.2 & 1.1 & 2.6 \\
\hline
\end{tabular}

\subsection{Analysis of the theoretical basis of the students' own situation}

Survey results show (Table3), Physical Education student theoretical foundation is weak, that their theoretical foundation of a good student survey only $23.6 \%$ target, while $76.4 \%$ of the students think that their theoretical foundation of general or poor. Since most of the physical education majors in college long ago admitted to participate in physical training, coupled with the impact of the management of sports specialty high school students in the presence of some irrational factors, to some extent, affected their theoretical learning. Theoretical foundation is weak, theoretical thinking ability is low, making them difficult to understand in theory after entering college class learning, difficult to accept, learn not Zhiyong, which led to decreased interest in learning, and ultimately produce student learning behavior escape theory courses.

Table3 List of Student Survey theoretical basis of its own cognition (\%)

\begin{tabular}{cccc}
\hline & Male & Female & Overall \\
\hline Good & 23.1 & 24.1 & 23.6 \\
General & 70.5 & 69.0 & 69.8 \\
Very poor & 6.4 & 6.9 & 6.6 \\
\hline
\end{tabular}

\subsection{Analysis of the Physical Education Teachers Teaching Content Availability}

To choose teaching content survey (Table4), there are $7.9 \%$ of the students thought the specialty sports theory class knowledge of teaching materials, $87.8 \%$ of students believe that the specialty sports theory class knowledge of materials combined with the actual content or expand combined. Most of the courses are based on statistics compiled textbooks Higher Education Press, almost all of 
the teachers are in accordance with the theoretical syllabus, according to the teaching content of teaching. With the expansion of the contents of the various disciplines, granted more and more content, textbooks and more thick, with no solid knowledge base of the students themselves, causing students to get the materials to produce the fear of hardship, it is difficult to stimulate students' interest in learning. Since the state of the teaching content of the reform, so that sports theory class space limited teaching materials, teaching content cannot be expanded to explain, students produce lack of theory courses and tasteless feeling, and therefore should be diversified materials form the main body of direction. In addition, in the course of learning theory, due to various conditions, the experimental class the proportion accounted for less than normal, resulting in the student's skills clearly insufficient.

Table4 content Professional Investigation List of teaching sports theory $(\%)$

\begin{tabular}{cccc}
\hline & Male & Female & Overall \\
\hline Teaching material & 9.0 & 6.6 & 7.9 \\
Teaching material with practice & 61.5 & 62.0 & 61.8 \\
Expand the teaching materials & 24.3 & 27.6 & 26.0 \\
From teaching materials & 5.2 & 3.5 & 4.3 \\
\hline
\end{tabular}

\subsection{Analysis of the situation of professional sports teaching methods theory teachers}

Methods of teaching survey (Table5), there are $70.8 \%$ of the students thought the teacher teaching the class uses a combination of content and teaching methods combined with multimedia teaching method. This shows that a single teaching method is simple, basically to explain the main teaching methods, theory with practice teaching or experimental arrangement less. In addition to teaching projectors use more widely, the use of other means much. Speaking on teaching teachers and students in mind, the next lesson back, the result is not a small student strenuous, not thoroughly understood, mind is not strong, especially for some abstract, cumbersome, complex and boring content, ignoring the cultivation of students' ability ; Physical Education Majors forthright, dynamic, enthusiastic classroom performance of specific teaching methods to visualize more interested in the performance class for the technical importance of the theory class contempt. In theory study, inattention, learning objectives are not clear, even the existence of professional theoretical learning not to learn it does not matter misconceptions. Furthermore, students learn lessons in theory, there is no deal with the relationship between good basic courses and specialized courses, the lack of theoretical knowledge to practical skills. In addition, since the characteristics of professional sports, the students in their daily study, theoretical courses and technical courses both open. Students in class learning technology, physical exertion is relatively large. So that students lose interest in learning, increase students' theoretical knowledge into practice run-time. Thus, showing students in the theory class energy shortage, if the theory of teaching, methods monotonous, it is difficult to fully mobilize the enthusiasm of students, which greatly affected the actual teaching effect Theory.

Table 5 List of teaching methods investigation (\%)

\begin{tabular}{cccc}
\hline & Male & Female & Overall \\
\hline Teaching & 11.5 & 10.2 & 10.9 \\
Teaching with Multimedia & 57.7 & 60.1 & 59.9 \\
Teaching with Practice & 25.6 & 25.6 & 26.6 \\
Teaching with Talking & 5.2 & 4.1 & 4.7 \\
\hline
\end{tabular}

\section{Conclusions and Suggestions}

\subsection{Conclusions}

Shaanxi Province College Physical Education Majors to learn professional theory courses indifferent attitude, motivation and self-utilitarian theoretical basis is weak influence students to learn 
professional theory courses subjective factors. Professional theory courses teaching content stale and dull, teaching methods are simple and lack of interest and attraction is affecting student learning theory class professional objective factors.

\subsection{Suggestions}

To strengthen the software and hardware construction of theory teaching

Continue to increase the construction of sports theory teaching hardware facilities, increase professional theory Teachers of quantity and quality. Perfect laboratory equipment, reasonable arrangements for experimental course, improve laboratory utilization.

Optimize curriculum structure, establish a new curriculum system

According to the standard curriculum requirements, select a higher practical textbook materials, do not unrealistic. Duration reasonable arrangements to avoid practical classes and class conflict theory, theory courses for students to teach professional to create a harmonious and comfortable atmosphere.

Teaching Reform

Classroom lectures streamline and strengthen teaching methods reform, highlighting the theory and practice of combining the basic theory courses and professional teaching theory class separation.

Correct attitude of students, increase students' interest in learning.

By all means carry out ideological and political education for students, professional students correct theory courses on changing attitudes, teaching methods, increase class fun so that students are willing to learn specialized theory courses.

\section{Reference}

[1] Zeng Ji, Wu Mingzhi, Li Zhiwei. Sports Theory Teaching Survey Analysis of Colleg,J.Physical Education Journal, 2007,14 (1): 95-98.

[2] Zhu Jianguo. Discussion on Teaching Reform of Teachers of Physical Education Theory,J. Zhejiang Sport Science, 2006,28 (4): 61-63.

[3] Lu Jinzhen. Specialist PE Theory Teaching problems and countermeasures, J. Education and Vocation, 2010, (27): 138-140.

[4] Zeng Xiaoli. Study on college sports theory teaching method,J Science and Technology Information, 2011 (15): 198.

[5] Wang Mingwei. Reason professional theoretical classroom sleepy phenomenon of sports majors analysis,J. Read and write (Education Journal), 2010,7 (9): 42.

[6] Lin Huijie. Course in College Physical Education Majors Learning Theory in Zhejiang Province,J. Hubei Sports Science, 2008, 27 (1): 95-96.

[7] Gao Chunhua. Research on the reasons for lack of interest of theoretical study of PE Students, J. Science and Technology Information, 2011, (27): 187.

[8] Li Shunan. Sports theory class selection techniques, J. Sports, 2011, (17): 59-60. 